\title{
Focusing on the young mind to create a psychologically healthier world for children
}

\author{
Deepthi Samarage ${ }^{1}$ \\ Sri Lanka Journal of Child Health, 2011; 40: 4-8
}

Our Chief Guest Dr. Firdorsi Mehta, WHO Representative for Sri Lanka, Guest of Honour Dr Ravi Ruberu, Secretary to the Ministry of Health \& Dr Mrs Dilrukshi Ruberu, Out going President Dr Kalyani Guruge, Past Presidents of the College, Members of the Council, Fellows and Members of the College, Professional Colleagues, Distinguished invitees, Ladies and Gentlemen. It is with a great sense of responsibility and humility that I stand before you, to accept my election as the President, Sri Lanka College of Paediatricians for the year 20102011. I pledge my absolute dedication and commitment to selfless service that will assure steady progress of child health care services of our country

Dr Firdosi Mehta, we are fortunate to have a person of your calibre as our Chief Guest. I thank you, Sir, for accepting our invitation and for your words of wisdom motivating us in our endeavours to foster child health in this country. Dr Ravi Ruberu, we are indeed grateful to you for being with us and your kind words of encouragement as the Guest of Honour despite your busy schedule as the Secretary to the Ministry of Health.

Health is defined as a state of complete physical, mental and social well-being and not merely the absence of disease. The term "mental health" is often confused with mental illness, or a mental disorder, and while they are related, mental health means much more than just the absence of mental illness. Childhood, from infancy through to adolescence, is the time when mental health is developed. Apart from basic physical needs such as food and shelter, children need enough love and security to make them feel safe, happy and confident. Whether these needs are fulfilled depends very much on how far the adults around young people at home, at school and in the community, can look after them, and create the right conditions for them to form satisfactory relationships,

${ }^{1}$ Senior Lecturer, Department of Paediatrics, Faculty of Medicine, University of Sri Jayawardenapura.

*Address given on Induction as President SLCP, September 2010 to make the most of their abilities and talents and to prepare them for taking on adult responsibilities.

Although infections still remain as a leading cause of morbidity and mortality in Sri Lanka, we are beginning to witness a shift in encounters in paediatric practice to chronic medical disorders, neurodevelopmental disorders, accidents and injuries, emotional and behavioural problems, drug and alcohol abuse, suicide, smoking and teenage pregnancies. This is a situation closer to that seen in industrialized countries

Mental well-being among children and teenagers is a priority for all those who work with children. It is time that we pay our attention to harness the mental well being of children and it is the reason for my selecting the theme for this year as "Focusing on the young mind to create a psychologically healthier world for children".

For years, there has existed a debate about whether nature or nurture plays a predominant role in child development. Nature refers to the inherited biological characteristics of an individual, such as their genes. Nurture refers to the influences in the environment that affects a child, such as the social environment of the family and the school. Modern psychologists suggest that we cannot look at these things exclusively. All children are different in their genetic make-up and development in children depends on the interaction between their genetic potential and the environment in which they grow.

Research strongly suggests that the way in which the brain develops is linked to early infant relationships, most often those with the primary carer. The first two years of life is considered to be the most sensitive period in child development. Children who were judged to be secure with their mothers in infancy are found to be more co-operative, more empathic, more socially competent, more interested in learning than children who were judged to have been insecure with their mothers in infancy. 
Children can experience all sorts of pressures and difficulties. Illness and disability suffered by the child or other members of the family, parental strains, financial hardships, violence at home, parents undergoing separation or divorce could result in serious emotional difficulties. It is not easy for children and young people to grow up in today's complex society. There is so much that is going on changes in values, new kinds of pressures in achieving excellence at competitive examinations and in the field of sport could have significant effects on a child's mental well being.

Industry spending on advertising to children has exploded in the past decade. With the help of wellpaid researchers and psychologists, advertisers now have access to in-depth knowledge about children's developmental, emotional and social needs at different ages. Using research that analyzes children's behaviour, companies are able to create sophisticated marketing strategies to reach young people.

Parents today are willing to buy more for their kids. Trends such as smaller family size and dual income mean that families have more disposable income. As well, guilt can play a role in spending decisions as time-stressed parents substitute material goods for time spent with their kids. Bullying and physical and sexual abuse can lead to a serious impact on child's mental well being. The transition from childhood to adolescence is a time of great change. During this period, young people experience significant physical and emotional development. They are confronted with many issues where they need to obtain new skills and their peer groups have the greatest influence on their lives.

Most young people transit through their adolescence well. However, some become more vulnerable and are at risk through a combination of their circumstances and risk-taking behaviour. They do not realise the potential harm. Without the right circumstances and support, problems may arise which can have a significant effect on a young person's future and can potentially lead to serious difficulties. These include poor educational achievements, anti-social behaviours, substance abuse, and adult mental health problems. All these are very costly for the individual and for the society at large. There is ample evidence in literature on the association of these adversities with child mental health problems. When things go wrong, children and young people can experience persistent and intense anxiety that disrupts daily routine and is a mental health problem that requires help. They may not sleep well, have nightmares / night fears, wet the bed and have difficulties in learning.

Some show withdrawal behaviour patterns. Others become aggressive and become disruptive in the classroom. They may develop eating problems and have trouble making friends and they may feel very sad and depressed and try to harm themselves, or even become suicidal.

Bullying is very common and probably happens in all schools. It can happen in many different ways. Victims find it difficult to defend themselves. Being bullied can seriously affect a child's mental health. Child sexual abuse is, sadly a too common experience. Sexual abuse happens to children and young people of all ages and cultures. It is often very difficult for the child to tell anyone about it, as the abuser may have threatened to hurt them if they tell anybody. A child may not say anything because they think it is their fault, that no one will believe them or that they will be teased or punished. The child may even love the abusing adult, they want the abuse to stop, but they do not want the adult to go to prison or for the family to break up. It can have both short term and longer term effects which can last into adulthood. No one can take away the memory of what happened, but with skilled help its impact can be reduced. Following sexual abuse children can develop a range of emotional and behavioural problems. When parents no longer love each other and decide to live apart, a child can feel as if their world has been turned upside down. A child may feel rejected and insecure or they may feel guilty \& worried about having caused the parental separation. Many fear being left alone and some may be angry at one or both parents for the breakdown in the relationship. The level of distress the child feels can vary depending on the age of the child, how much they understand and the support they get from parents, family and friends. Many children hold onto a wish that their parents may get back together.

A child with a specific learning difficulty is as able as any other child, except in a particular area of learning. It may be difficult for parents and teachers to realize that a child has this sort of problem as vey often their development has progressed without any concern in the early years. There are many different types of specific learning difficulty but the best known is probably dyslexia. In dyslexia, the child has difficulty with spelling and reading. Others include difficulties in writing, mathematical concepts and motor clumsiness. 
- They may struggle keeping up with classmates, and may come to see themselves as stupid or no good.

- They may find it difficult to concentrate on lessons may not be able to follow them properly,

- They may complain of lessons being 'boring'.

- The child may search for other ways to pass the time and to succeed.

A specific learning difficulty is not a mental illness. However, children with a specific learning difficulty are more likely to develop mental health problems. The difficulties will impact on educational progress and self esteem and suggest the child has greater academic difficulties than is actually the case. Proper assessment offered by educational psychologists and management offered at correct time will immensely benefit these children to achieve their optimum potential in learning.

It is well recognized that helpful interventions in people's lives often come too late to make a major difference. Much research points to the importance of early intervention and to the need for multi-faceted strategies in programmes of prevention. Support should be in place before the child's emotional development has been compromised.

Patterns of interaction are transmitted more or less faithfully from one generation to the next. Children tend unwittingly to identify with parents and therefore adopt, when they become parents, the same patterns of behaviour that they themselves have experienced during their own childhood. If we want to help the next generation we should be working with their parents while they are children now.

\section{What should be our role?}

- $\quad$ Management of child mental health issues Many paediatricians and primary care family physicians are good generalists in providing care for child mental health issues and the mental health specialists should be seen as a specialist extension of their expertise.

- Collaboration for training specialists in child mental health

Adult psychiatrists are more likely to focus on adult patients and they may not possess childoriented perspectives. Currently, the numbers of adult psychiatrists who have special interest in child psychiatry and practicing child psychiatry are very few and we need to collaborate with our psychiatrist colleagues on developing specialists trained in child mental health.

- Promotion/advocacy for training in educational psychologists

Lack of educational psychologists in our education system needs to be addressed and we need to collaborate or play an advocacy role to the authorities of the Department of Education in development of this extremely important group of expertise in an education system and also strengthening the training of special education teachers.

- $\quad$ Parent and teacher guides

It is imperative that parents and teachers have awareness of the needs of the children during every single phase of their development to create the right environment to successfully navigate them throughout their childhood into healthy, happy and productive citizenship. Parent/Teacher guidelines with precise information suited to our society would be quite helpful to overcome difficult situations in parenting which could be quite demanding at times.

- Collaboration/ advocacy role in strengthening social and emotional learning programmes in schools and healthy school concepts

Over the last decade many countries have adopted programmes to build the capacity of schools and early childhood education and care settings to support the mental health and wellbeing of children and young people. Research has clearly demonstrated the significant role of social and emotional learning programmes (SEL) in schools. It is shown that SEL programmes lower levels of emotional distress that interfere with learning, lowers disruptive behaviour, lowers alcohol, tobacco or other drug use and also fosters healthy development and academic achievement of all students. The development of such programmes involves the collaboration of health and education experts and professional development of teachers is fundamental in such programmes.

Mental health promotion is much more than simply inserting curriculum materials into health and should be based on the understanding that young people need to engage actively with ideas and concepts in order to learn. The classroom materials for activities should be incorporated and should place the student at the centre of activities, positioning the teacher as a facilitator. Areas to cover in such programmes include self-awareness which include identifying and 
recognizing emotions, accurate self-perception, selfmanagement with strategies for impulse control and stress management, self-motivation, discipline and social awareness which include empathy and respect for others.

In order to prevent violence in relationships and families, there are reasons to focus efforts on children and young people. Perhaps the most obvious rationale for 'starting young' is that it can have a lasting effect on children's and young people's later relationships. Adolescence is a crucial period in terms of women's and men's formation of respectful, non-violent relationships later in life.

\section{Other child health priorities}

While focusing on activities related to the theme, we would place emphasis on certain areas which need quick wins. Recent epidemics of dengue have caused a shock wave around the country recording a total number of deaths as high as 316 during the year 2009 and 229 up to date in the year 2010. It is known that only a minority of patients infected with dengue virus will develop the severe disease called dengue haemorrhagic fever or DHF. While the government and public campaign for prevention, health care professionals focus on improving case management to reduce the fatalities.

In this regard, with the assistance of the World Health Organization, a team of paediatricians and physicians have been trained in dengue management recently at a centre of excellence in Thailand. Leakage of plasma into the body cavities during the critical phase of the illness is the hall mark of severe dengue. New concepts pay emphasis on fluid regimes in the management of the critical phase which last only for 1- 2 days. As the rate of leaking will vary from patient to patient, meticulous monitoring and titration of fluids is crucial to avoid two main reasons for the deaths, namely shock and fluid overload. Patients should be managed in high dependency units during epidemics and adequate equipment and staff to monitor should be made available.

Sri Lanka College of Paediatricians has collaborated with the Epidemiology Unit of the Ministry of Health to revise and update the national guidelines. These guidelines will be distributed throughout the country to disseminate the latest developments. All categories of healthcare staff will be trained to improve case management. Along with the Ministry of Health and the other professional colleges we will make all efforts towards a goal of reducing the case fatality rates significantly to levels comparable to centres of excellence in the region. We intend to play a more proactive role when collaborating with the relevant departments of the Ministry of Health and also other organizations such as WHO/UNICEF/ National Child Protection Authority (NCPA) on epidemiological research, policy decisions, activities and programmes related to child health care services and public health interventions.

For a professional body, the need to avoid a disconnection between one tenure of office and the other cannot be over-emphasized. As leadership is a continuum, we will resuscitate the culture of rolling plans by working through subcommittees in key areas related to child health care.

\section{Millennium development goals}

Vital registration data suggest that we are on track in achieving our targets on Millennium Development Goals to reduce child mortality by two-thirds. Although more reliance could be placed on vital registration and Family Health Bureau data, the College will make efforts towards making careful observations on the concerns expressed regarding disparities and relatively higher figures of infant mortality rate expressed in 2006/07 Demographic and Health Survey.

WHO and UNICEF Child Health Epidemiology Reference Group 2008 global estimates of causes of deaths in under 5 age group include $40 \%$ deaths attributed to causes within the newborn period. Estimates for Sri Lanka show a figure as high as $60 \%$ of deaths attributed to causes in the neonatal period. As Sri Lanka demonstrates far better child health indices in comparison to our neighbours in the developing world, we need to focus on appropriate newborn, and child health interventions specific to our country rather than adopting blanket measures recommended in general to the developing world. If we are to reduce child mortality further we need to begin with strengthening the mechanisms of effective recording and collecting up-to-date information on the causes of neonate/infant /child deaths. The College will collaborate with relevant stakeholders in pursuing this endeavour.

\section{Continuing professional development}

We will continue to harness Continuing Professional Development of its members and other health care professionals such as nurses and midwifes. Particular emphasis will be given to advanced paediatric life support courses. A team of local paediatricians has been trained as trainers by a faculty from Australian 
Paediatric Life Support Group. The second of the training programmes of training of trainers, by the same team, is scheduled to be held in February 2011. Academic meetings and training courses conducted by the College will be continued and strengthened.

Event of today will be more meaningful and rewarding if the goals I articulated so faithfully above are fully accomplished within the next twelve months. I earnestly solicit the guidance from the Past Presidents and request support and cooperation of members of the Council to achieve our set goals. As a team, we can overcome all odds and build a profession whose service will remain valued by the society at large. I will consult far and wide and ensure that the College remains member-friendly and we will harness ideas and talents from members and think outside of the box in order to take the Institute to greater heights.

\section{Appreciations}

On this important day in my academic career, I seek your indulgence to pay tribute to all those who have mentored, inspired, encouraged, supported and believed in me. I owe a great debt of loving gratitude to my late father and my mother. Batch mates of my brothers who are in this audience would recall attending my father's funeral as $1^{\text {st }}$ and $2^{\text {nd }}$ year medical students in 1971. I was only 13 years old and my great mother was only 46 years old then. She very bravely faced many hardships and made huge sacrifices in her life to ensure that we reach our optimum potential in our educational pursuits. My dear mother, I wish to honour your commitment and dedication by offering to serve in this prestigious position to advance the child health care in this country.

I recall with great appreciation all my teachers who have mentored me during my primary education, medical school and during my training in paediatrics. I had the fortune of laying the foundation for a career in paediatrics under the able guidance of great teachers in the calibre of Prof. Priyani Soyza, Prof. Narada Warnasuriya and late $\mathrm{Dr}$ Jasmine Nanayakkara. I extend my heartfelt gratitude to all of them and many other senior paediatricians from whom I have learnt and who inspired me during my career. I wish to thank Prof. Jayantha Jayawardene Dean of Faculty of Medical Sciences/USJP and my colleagues in the University for all the support extended to me during the last year and weaning me off from all the responsibilities I have been shouldering at the university. Your kind and generous support has made it possible for me to overcome my grief, ease out the problems in my personal life and stand here today reverting back to my professional responsibilities.

I thank Dulani, Rohitha, Guwani, \& Manouri for creating a friendly working environment in the department of Paediatrics at the Jayawardenepura University. I thank Child Psychologist Mrs Nishali Fernadopulle for her inputs to my presentation today. I wish to extend a very special word of thanks to my close friends since my school days Manju, Udayangani, Shivanthi, Chandri \& Sepalika who have always been with me sharing my life. My brother Sarath, you have been a tower of strength in my academic career particularly in my administrative responsibilities. My brother Upali, you have always been more than a brother to me and I never felt the loss of my father at such a young age because of you. Among many unfortunate things in my life I consider myself indeed fortunate to have wonderful brothers like you. I thank all three of you most sincerely. My loving son Danidu, I thank you for all the joys of motherhood you have given me and I am so proud of what you are today courageously withstanding all the adversities which came your way.

Ladies and gentlemen I am indebted in my life to a person who has brought me much happiness in my life and contributed so much to my career. Twenty years ago as a young wife who wished to be around her husband all the time I told him that I want to take up the post of District Medical Officer at Maskeliya Hospital. He asked me whether I am that foolish and told me that one should always try to accomplish the fullest potential in one's career. $\mathrm{He}$ always encouraged me throughout my academic career and his friends who are here today would vouch for the fact how proud he was in my academic achievements. Ladies and gentlemen, it is pertinent that I register my profound appreciation of my late husband Muni, whose support and passion for excellence spurred me through my career. By burying my deep and intense pain, I offer my services to children in this country as a gesture of honouring him for all that he believed in the cause of humanity. Finally, I wish thank all of you who are here today for honouring us with your presence. 